OPEN ACCESS

Edited by:

Xavier Martini,

University of Florida, United States

Reviewed by:

Vasuki Belavadi,

University of Agricultural Sciences,

Bangalore, India

Johannes Stökl,

Justus Liebig Universität Gießen,

Germany

${ }^{*}$ Correspondence:

Antonino Cusumano

cusumanoantonino@tiscali.it

Specialty section: This article was submitted to

Chemical Ecology,

a section of the journal

Frontiers in Ecology and Evolution

Received: 13 October 2017 Accepted: 13 December 2017

Published: 09 January 2018

Citation:

González JM, Camino D, Simon S and Cusumano A (2018) Semiochemical Exploitation of Host-Associated Cues by Seven Melittobia Parasitoid Species: Behavioral and Phylogenetic Implications. Front. Ecol. Evol. 5:172. doi: 10.3389/fevo.2017.00172

\section{Semiochemical Exploitation of Host-Associated Cues by Seven Melittobia Parasitoid Species: Behavioral and Phylogenetic Implications}

\author{
Jorge M. González ${ }^{1}$, Dakota Camino ${ }^{1}$, Sabrina Simon ${ }^{2}$ and Antonino Cusumano ${ }^{3 *}$ \\ ${ }^{1}$ Department of Plant Sciences, California State University, Fresno, Fresno, CA, United States, ${ }^{2}$ Biosystematics Group, \\ Wageningen University and Research, Wageningen, Netherlands, ${ }^{3}$ Laboratory of Entomology, Wageningen University and \\ Research, Wageningen, Netherlands
}

Chemical compounds (infochemicals or semiochemicals) play an important role both in intra-specific and inter-specific communication. For example, chemical cues appear to play a key role in the host selection process adopted by insect parasitoids. In recent years significant advances have been made in order to understand the chemical ecology of insect parasitoids. However, little information is available about the evolution of semiochemical use in the host location process of insect parasitoids. Here we investigated the strategy adopted by seven closely related parasitoid species in the genus Melittobia when foraging for four different suitable hosts. By using an integrated approach that combined olfactometer bioassays and phylogenetic investigations, we found that: (1) exploitation of host-derived semiochemicals is widespread in the Melittobia genus; (2) there is specificity of attraction toward the different host species tested; in particular, the early-branching species in the Melittobia genus are attracted to odors associated with leaf cutting bees (Megachile rotundata) whereas the most-diverged species are attracted to odors associated with solitary mud dauber wasps (Trypoxyilon politum). Regardless of the phylogenetic relationships, no Melittobia species exhibited attraction toward odors of factitious laboratory hosts (i.e., the flesh fly Sarcophaga bullata). Interestingly, five Melittobia species are also attracted by odors associated with honeybees hosts which indicate that these parasitoids could be potential pests of honeybees. Our study shed light on the host location within the Melittobia genus and represents a first attempt to understand semiochemical use in an evolutionary perspective in the context of parasitoids' foraging behavior.

Keywords: infochemicals, parasitic wasps, host location process, Hymenoptera, Eulophidae

\section{INTRODUCTION}

Semiochemicals are important sources of information that mediate ecological interactions in organisms at different degree of evolution across microorganisms, plants, arthropods, and vertebrates (Hildebrand, 1995; Carde and Millar, 2004). Semiochemicals play a role both in intraspecific and inter-specific communication (Dicke and Grostal, 2001; Wyatt, 2003). Within a species, 
semiochemicals can be exploited to find and choose a mate, to mark the territory, for kinship recognition or to inform others of danger. Between species, semiochemicals can be used by natural enemies to locate preys/hosts and are widely exploited by parasitoids, i.e., insects whose eggs and larvae develop inside the body of other arthropods whereas the adult is free-living (Godfray, 1994; Fatouros et al., 2008; Colazza et al., 2014). In fact, for parasitoids, there is a direct link between host encounter and the production of offspring. Consequently, natural selection is expected to act strongly on parasitoids' host finding efficiency (Vet, 2001). Species that display high host finding efficiency may have an advantage when competing with antagonistic parasitoid species that are searching in the same habitat, especially if hosts are scarce (Harvey et al., 2013; Cusumano et al., 2016).

In recent years significant advances have been achieved toward understanding which cues are used by female parasitoids to locate hosts (Fatouros et al., 2005; Hilker and Meiners, 2006). Parasitoids can exploit host-associated cues including frass, honeydew, wing scales, footprints, silk and mandibular gland secretions (Chabi-Olaye et al., 2001; Thibout, 2005; Mehrnejad and Copland, 2006; González et al., 2011; Iacovone et al., 2016). In addition, parasitoids attacking herbivores rely widely on herbivore-induced plant volatiles (Mumm and Dicke, 2010). However, less is known on the evolutionary history of semiochemicals use in the context of host location by insect parasitoids. Theoretical models on the evolution of host selection have been developed but these models focused on the spatial distribution on host resources and do not take into account the exploitation of semiochemicals when parasitoids search for hosts (Charnov and Stephens, 1988). Phylogenetic approaches have been useful to investigate several evolutionary questions including historical pattern of host shifts (Cook et al., 2002) and host range specialization (Stireman, 2005) but the evolution of semiochemical use has never been considered in these studies. To implement data on semiochemical exploitation into phylogenetic analyses, the host location process of multiple closely related species must be studied. This was the purpose of this study, in which we used an integrated approach to investigate the host finding process of different parasitoid species within the genus Melittobia (Hymenoptera: Eulophidae), inferred their phylogenetic relationships and traced host location process on the phylogeny.

Melittobia wasps are small $(1.0-1.5 \mathrm{~mm})$ ectoparasitoid idiobionts that develop gregariously on their hosts (Matthews et al., 2009). They exhibit sexual dimorphism and females are polymorphic (short-winged and long-winged; González et al., 2004a; González and Matthews, 2005a). Long-winged females, also called macropterous females, are the dispersal individuals in all Melittobia species, while some non-dispersing short-winged females, also known as brachypterous females, may be produced in order to fully exploit large high quality hosts (Matthews et al., 2009). van den Assem et al. (1982) and Dahms (1984) placed all Melittobia species in four species-groups based on male displays during courtship and morphological characteristics, respectively. According to Tanner et al. (2011), the 12 known Melittobia species are classified in four phylogenetically-distinct groups ranging from most primitive to more advanced in the following order: assemi species-group (2 species), hawaiiensis species-group (2 species), clavicornis species-group (1 species), and acasta species-group (7 species). Melittobia wasps tend to be polyphagous and they are usually recorded as natural enemies of solitary wasps and bees, such as mud dauber wasps in the genera Trypoxylon (Crabronidae) and Sceliphron (Sphecidae) and several cavity-nesting bees including important pollinators such as megachilid leaf-cutter bees (Krombein, 1967; Matthews et al., 2009). Melittobia have been also occasionally recorded to attack honey bees as well as several insects from different orders and can reproduce fine in factitious hosts (i.e., flesh flies) (Matthews et al., 2009). The ancestral host of Melittobia species is not known but it is possible that some solitary cavity-nesting bees which nested in aggregated situations are closely related to the original natural hosts, from which the host range could have been expanded to include solitary wasps such as mud dauber wasps which are notable because females tend to build nests in clusters (Malyshev, 1968; Cross et al., 1975; Molumby, 1995). Up-to date, only the host location process of 2 species of the acasta species-group ( $M$. digitata and $M$. acasta) has been investigated showing that long-winged females are attracted by volatile semiochemicals emitted by the cocoons of mud dauber wasps (Cusumano et al., 2010) and megachilid leaf-cutting bees (Silva-Torres et al., 2005a,b; Glasser and Farzan, 2016) which envelop the host prepupa, i.e., the host stage attacked. However, it is not known whether the other Melittobia species have evolved a similar host location strategy based on exploitation of hostassociated chemical cues.

In this study we first investigated the host location process of seven different Melittobia species belonging to the four speciesgroups using a comparative approach based on olfactometer experiments and reconstructed evolutionary relationships in terms of host odor attraction among seven Melittobia species. We explored the behavioral responses of those wasps within four species-groups toward host-associated volatiles emitted by both naturally parasitized hosts (the organ-pipe mud dauber, the alfalfa leaf-cutter bee and the honeybee) and factitious hosts (flesh flies). We hypothesized that the different species of Melittobia exploit host-specific semiochemicals when foraging for natural hosts. On the contrary no attraction to host-associated odors is expected for factitious hosts. To the best of our knowledge, this study represents the first attempt to investigate semiochemical use within a taxonomic unit to shed light into the evolutionary history of parasitoids' host location process.

\section{MATERIALS AND METHODS}

\section{Insect Cultures \\ Parasitoids}

All Melittobia species (assemi group: M. assemi and M. sosui; hawaiiensis group: M. cf. hawaiiensis and M. australica; clavicornis group: M. clavicornis; acasta group: M. acasta and M. digitata) were reared on naked prepupae of Trypoxylon politum from stock cultures maintained at the Department of Plant Science facilities, California State University, Fresno, in Fresno, California. Cultures were established from material originally maintained at the University of Georgia, Department 
of Entomology, Athens, Georgia, and the Entomology Research Laboratory of Texas A\&M University, College Station, Texas. Our stock cultures were maintained under controlled conditions in a growth chamber $\left(25^{\circ} \mathrm{C} ; 60 \pm 10 \%\right.$ R.H.; 14L:10D $)$. Healthy hosts were collected from their nests; prepupae were excised from cocoons and exposed to parasitoids. Only long-winged females $<5$ days-old were used in the experiments. Because of their age and since they were taken directly from the cultures prior to their use in the bioassays, female parasitoids were assumed to be mated. About 1-2 $\mathrm{h}$ before bioassays, the Melittobia wasps were taken from cultures and individually placed in size 1 gelatin capsules ( $0.5 \mathrm{ml}$ volume, $6.63 \mathrm{~mm}$ in diameter).

\section{Hosts}

The following hosts were cultured in order to be used in the bioassays:

\section{Apis mellifera (Hymenoptera: Apidae)}

Honeybees are rare hosts of Melittobia species but they have been reported to be attacked by M. acasta and other Melittobia species (Hobbs and Krunic, 1971; Erickson and Medenwald, 1979; Jelinski and Wojtowski, 1984; de Wael et al., 1995; González et al., 2004a; Matthews et al., 2009) (see Supplementary Table 1 for host-parasitoid associations reported in the field and/or in the lab). Combs containing open and recently capped cells with larvae and prepupae of honeybees were obtained from two sources: the No Walls Busy Bee Honey Farm, Fresno, CA, and T \& A Farms, L.A., CA, USA.

\section{Megachile rotundata (Hymenoptera: Megachilidae)}

Alfalfa leaf-cutter bees can be attacked by M. acasta and other Melittobia species in the field, especially in areas where the bee is used for pollination (Hobbs and Krunic, 1971; Farkas and Szalay, 1985; González and Matthews, 2002; González et al., 2004a; Matthews et al., 2009). The bees were obtained as diapausing prepupae inside the cocoons from Pioneer Hybrid International, Namper, ID, USA.

\section{Trypoxylon politum (Hymenoptera: Crabronidae)}

Organ-pipe mud dauber wasps are natural hosts of Melittobia species and they are frequently found parasitized by M. australica, M. acasta, and M. digitata (González et al., 2004a,b; González and Matthews, 2005a; Matthews et al., 2009). Mud dauber wasps prepupae were obtained from nests collected at one of our traditional collecting sites (González et al., 1985; Matthews et al., 1985) (Watson Mill Bridge, near Comer and Carlton, Georgia, $34.0261^{\circ} \mathrm{N}, 83.0731^{\circ} \mathrm{W}$ ). The wasps' prepupae remain in diapause and viable if kept in a refrigerator $\left(8-12^{\circ} \mathrm{C}\right)$.

\section{Sarcophaga (Neobellieria) bullata (Diptera: Sarcophagidae)}

Flesh flies are factitious hosts of several species of Melittobia wasps and they are currently used in commercial production of $M$. digitata (Matthews et al., 2009). The flesh flies used in our trials were obtained from a commercial source (Carolina Biological Supply Company, Burlington, NC, USA).

All hosts were kept in a refrigerator at $<10^{\circ} \mathrm{C}$ to maintain them, especially prepupae of mud dauber wasps, in diapause to avoid their development.

\section{Stimuli Tested}

Volatile semiochemicals emitted by different hosts of Melittobia were tested in dual choice conditions using always clean air as control. The treatments were: (1) Apis mellifera prepupae, which were removed from their cells with soft forceps; (2) Megachile rotundata prepupae inside cocoons which were cut at the tip with a micro scissor, to confirm the stage and quality of the hosts; (3) Trypoxylon politum prepupae enveloped inside cocoons gently broken at the subtruncate cap in order to open a small orifice to verify that the prepupae was healthy and not parasitized; (4) Sarcophaga (Neobellieria) bullata pupae inside their puparia.

\section{Y-Tube Olfactometer Behavioral Assays}

The response of macropterous females of seven Melittobia species toward host-related volatile semiochemicals was investigated using a Y-tube olfactometer made up of polycarbonate (stem: $90 \mathrm{~mm}$ long; arms: $80 \mathrm{~mm}$ long, with an angle of $130^{\circ}$ in between; inner diameter: $15 \mathrm{~mm}$ ) sandwiched between two glass sheets. A $10-\mathrm{mm}$ diameter hole was drilled through the device into the end of each arm to allow the connection with air tubes and the introduction of the test wasp.

Medical-grade compressed air was passed through the tubes connected to both arms of the Y-tube. The incoming air was regulated by flowmeters at $35 \mathrm{ml}$ per min, based on previously published information on similar tests done with $M$. digitata showing that the wasp's walking behavior was optimal at such a low rate (Cusumano et al., 2010). Before reaching the arms of the Y-tube apparatus, air was purified by a charcoal filter and humidified by bubbling into distilled water flasks. The Y-tube was illuminated from above with red fluorescent lights (40-W fluorescent bulbs covered with red tube guards) keeping visibility in accordance to parameters previously established by González et al. $(1985,2011)$ and Matthews et al. (1985). To avoid visual or physical cues, the host species tested were enclosed in a small nalgene cylinder $(12 \times 9 \mathrm{~mm})$ with copper wire mesh $(18$ Standard US mesh) on both sides. The cylinder with the host test choice was randomly placed close to the edge of one of the arms, while an empty one was used as control in all bioassays and placed at the other arm. A female wasp was gently introduced inside the Y-tube olfactometer at the bottom of the stem and it was allowed to explore for 900 s before being discarded.

The wasps' behavior was measured in terms of first choice, i.e., the first time wasps crossed a virtual line, defined in each arm at $4 \mathrm{~cm}$ distal to the bifurcation of the Y-tube olfactometer, and remained for at least $30 \mathrm{~s}$. The bioassays were performed in blocks according to the stimuli tested (T. politum, M. rotundata, A. mellifera, and S. bullata). Test combinations with 7 different Melittobia species were randomized within each block. For each tested combination 46-54 successful replicates were performed, indicating that wasps were replaced if a no-choice was scored after $900 \mathrm{~s}$. Between replicates the odor source was renewed and the position of test and control were switched to avoid possible biases between both arms. The walking behavior of every tested Melittobia wasp was observed with a video Camera (Logitech Carl Zeiss Tessar HD 1080P) connected to a PC (Dell Optiplex 790) with a Monitor (19", Model 1908FP, Dell), in order to observe the wasps away from the Y-tube and avoid possible interference from the observer on the walking behavior of the 
Melittobia wasp being tested. The room was kept at $20^{\circ} \mathrm{C}$ and $60 \% \mathrm{RH}$. All experiments were conducted from 8:00 to $12: 00 \mathrm{~h}$ and from 13:00 to 17:00 h.

In Y-tube olfactometer experiments, the number of wasp females that made a response was analyzed by $\chi^{2}$ test. We tested whether the observed distribution of responding wasps significantly diverged from a 50:50 distribution which is expected if the wasps do not display any attraction toward the tested odors. All data were analyzed using STATISTICA7 software (StatSoft, 2001).

\section{Evolutionary Relationships in Parasitoids' Host Location Mediated by Semiochemicals \\ Sampling}

To reconstruct the evolutionary relationships of host location among the seven Melittobia species, available sequences of several Melittobia species as well as sequences from outgroup species were downloaded from NCBI GenBank (accession numbers JF924912-JF925004). We further extracted DNA from ethanol (98\%) preserved M. cf. hawaiiensis species using the DNeasy Blood and Tissue kit from Qiagen. We amplified the Internal Transcribed Spacer (ITS) regions 1 and 2 of the nuclear rRNA using the primer sequences as provided in Tanner et al. (2011). The amplification profile was as follows: $5 \mathrm{~min}$ at $95^{\circ} \mathrm{C}, 35$ cycles of $30 \mathrm{~s}$ at $95^{\circ} \mathrm{C}, 45 \mathrm{~s}$ at $58^{\circ} \mathrm{C}$ and $2 \mathrm{~min}$ at $72^{\circ} \mathrm{C}$ for elongation, and a final extension of $5 \mathrm{~min}$ at $72^{\circ} \mathrm{C}$. We further amplified the Cytochrome Oxidase 1 (CO1) barcode region of the mtDNA using the universal invertebrate Folmer primers LCO1490- CO2198 (Folmer et al., 1994). The amplification profile was as follows: $5 \mathrm{~min}$ at $95^{\circ} \mathrm{C}, 35$ cycles of $30 \mathrm{~s}$ at $95^{\circ} \mathrm{C}, 45 \mathrm{~s}$ at $50^{\circ} \mathrm{C}$ and $2 \mathrm{~min}$ at $72^{\circ} \mathrm{C}$ for elongation, and a final extension of $5 \mathrm{~min}$ at $72^{\circ} \mathrm{C}$. PCR products were checked and the size was determined by agarose gel electrophoresis. PCR products were purified with Qiagen's QIAquick Gel Extraction Kit and sequencing reactions were carried out by Eurofins. The newly generated $M$. cf. hawaiiensis gene sequences are publicly available (GenBank accession numbers MG263513-MG263515).

\section{Phylogenetic Analysis}

Compared to the study of Tanner et al. (2011) we included the three newly generated sequences of $M$. cf. hawaiiensis in our taxon sampling for the phylogenetic analyses. In addition, we applied a more extensive maximum likelihood (ML) analyses including FreeRate models and performing independent tree searches (see below). First, individual gene alignments were generated using MAFFT v7.122b (Katoh and Standley, 2013) and subsequently concatenated using FASconCAT v1.0 (Kück and Meusemann, 2010). The concatenated alignment was subjected to maximum likelihood (ML) and Bayesian analyses (BI). For the ML analysis we first used IQ-TREE v.1.5.0 (Nguyen et al., 2015) to perform an extended model selection that additionally includes FreeRate models (-m TESTNEWONLY) for each gene partition (-spp) (697 bp: CO1, 1,798 bp: ITS1, 726 bp: ITS2). The assumed model of nucleotide substitution was $\mathrm{K} 3 \mathrm{Pu}+\mathrm{R} 3$ for $\mathrm{CO} 1, \mathrm{~K} 2 \mathrm{P}+\mathrm{G} 4$ for ITS1, and TIM3e+R3:
ITS2. We further selected the tree with the best log-likelihood score found in 50 completely independent tree searches using IQ-TREE v.1.5.0 (Nguyen et al., 2015; Chernomor et al., 2016). Support values for ML trees were estimated with 100 bootstrap replicates.

The BI analysis was conducted with MrBayes v.3.2.6 (Huelsenbeck and Ronquist, 2001; Ronquist and Huelsenbeck, 2003) similar to the approach as in Tanner et al. (2011) with ITS1 and ITS2 partitioned according to the general time-reversible model with gamma-distributed rate variation across sites (GTR $+\Gamma$ ), and CO1 partitioned according to the general timereversible model with invariant sites and gamma-distributed rate variation across sites $(\mathrm{GTR}+\mathrm{I}+\Gamma)$, and with all parameters independent across loci. The matrix was analyzed over 3,000,000 generations using four chains (one cold, three heated) and a sampling frequency of 100 . The average standard deviation of the split frequencies was below 0.01 and the first 250,000 trees were discarded as the "burn-in." The remaining trees were assembled into a topology.

\section{Ancestral Character Reconstruction and Evolutionary Relationships in Host Location}

We used SIMMAP v.1.5 (Bollback, 2006) and Mesquite v.3.2 (Maddison and Maddison, 2017) to reconstruct the evolution of host preferences among the seven Melittobia species. In SIMMAP our model was constructed such that the bias parameter for the discrete characters was equal $(1 / \mathrm{k})$ prior, all states were unordered, and the gamma distribution prior had a value of 1.25 and a b value of 0.25 with 60 categories. In Mesquite we used Maximum likelihood algorithms to reconstruct character evolution with the default probability models. In these analyses, we used the wasps' behavior measured in terms of first choice, which was defined as described above.

\section{RESULTS}

\section{Olfactometer Experiments: Wasp Responses to Host Semiochemicals Apis mellifera}

Five species of Melittobia showed a significant attraction to volatiles released by prepupae of $A$. mellifera (Figure 1A). The early-branching Melittobia species (M. assemi: $\chi^{2}=3.92, d f=1$, $P=0.048 M$. sosui; $\left.\chi^{2}=8.00, d f=1, P=0.005\right)$ were attracted by host-associated volatiles. Among the more-diverged species, $M$. cf. hawaiiensis $\left(\chi^{2}=5.12, d f=1, P=0.024\right)$ and $M$. clavicornis $\left(\chi^{2}=5.12, d f=1, P=0.024\right)$ significantly preferred volatiles emitted by $A$. mellifera when tested against clean air. In the case of $M$. acasta, a species belonging to the most evolved group, such preference was highly significant $\left(\chi^{2}=28.88, d f=1, P<0.001\right)$. No significant attraction was found for $M$. australica $\left(\chi^{2}=2.88, d f=1, P=0.090\right)$ or M. digitata $\left(\chi^{2}=2.88, d f=1, P=0.090\right)$.

\section{Megachile rotundata}

Three species of Melittobia were significantly attracted by volatiles released by cocoons containing $M$. rotundata prepuae (Figure 1B). Interestingly only the early-branching species 


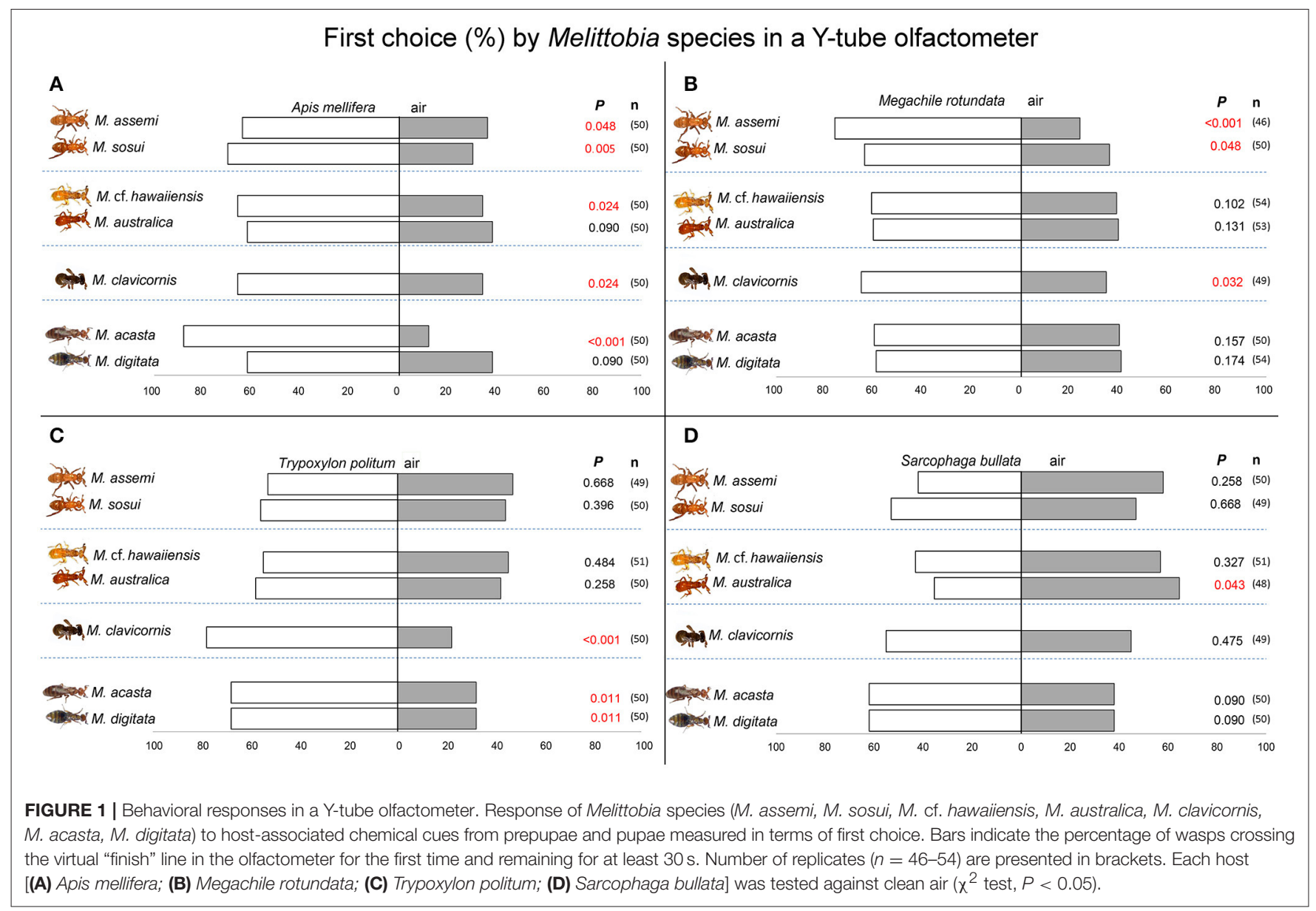

(M. assemi: $\chi^{2}=12.52, d f=1, P<0.001 ;$ M. sosui: $\chi^{2}=3.92$, $d f=1, P=0.048$ ) and the more diverged $M$. clavicornis $\left(\chi^{2}=4.592, d f=1, P=0.032\right)$ showed such attraction, whereas species belonging to the most diverged group (M. acasta: $\chi^{2}=2.00, d f=1, P=0.157 ; M$. digitata: $\chi^{2}=1.85, d f=1$, $P=0.174$ ) did not prefer volatiles emitted by $M$. rotundata when tested against clean air. Additionally species of the hawaiiensis group ( $M$. cf. hawaiiensis: $\chi^{2}=2.67, d f=1, P=0.102$; M. australica: $\chi^{2}=2.28, d f=1, P=0.131$ ) were also not attracted.

\section{Trypoxylon politum}

Three species of Melittobia significantly responded to volatiles emitted by prepupae of T. politum (Figure 1C). Interestingly, species at the bottom of the evolutionary scale such as the early branching Melittobia (M. assemi: $\chi^{2}=0.18$; $d f=1, P=0.668$; M. sosui: $\left.\chi^{2}=0.72 ; d f=1, P=0.396\right)$ and the species of the hawaiiensis group (M. cf. hawaiiensis: $\chi^{2}=0.49$; $d f=1$, $P=0.484 ; M$. australica: $\left.\chi^{2}=1.28 ; d f=1, P=0.258\right)$ did not show a behavioral response. On the contrary, the most diverged species (M. acasta: $\chi^{2}=6.48 ; d f=1, P=0.011 ; M$. digitata: $\left.\chi^{2}=6.48 ; d f=1, P=0.011\right)$ as well as $M$. clavicornis $\left(\chi^{2}=15.68\right.$; $d f=1, P<0.001)$, significantly preferred volatile semiochemicals emitted by $T$. politum prepupae over clean air.

\section{Sarcophaga bullata}

No significant attraction toward volatiles emitted by S. bullata was shown by the seven tested Melittobia species (Figure 1D). In fact a slight, but significant, avoidance effect was found in M. australica ( $\chi^{2}=4.03 ; d f=1, P=0.043$ ) whereas the other species did not show any preference in the Y-tube olfactometer (M. assemi: $\chi^{2}=1.28, d f=1, P=0.258 ;$ M. sosui: $\chi^{2}=0.184$, $d f=1, P=0.668 ; M$. cf. hawaiiensis: $\chi^{2}=0.961$, $d f=1$, $P=0.327 ;$ M. clavicornis: $\chi^{2}=0.51, d f=1, P=0.475 ; M$. acasta: $\chi^{2}=2.88, d f=1, P=0.090 ; M$. digitata: $\chi^{2}=2.88, d f=1$, $P=0.090)$.

\section{Evolutionary Relationships in Parasitoids' Host Location Mediated by Semiochemicals}

Our phylogenetic analyses further support the Melittobia speciesgroup concept as proposed by van den Assem et al. (1982) and Dahms (1984) (Figure 2). Tanner et al. (2011) also supported based on molecular analyses the M. assemi speciesgroup, confirming the sister-group relationship of $M$. assemi and $M$. sosui, the $M$. acasta species-group, confirming the sister-group relationship of $M$. acasta to $M$. megachilis and $M$. digitata, and the M. clavicornis species-group. Based on our more extensive maximum likelihood analyses, we could 


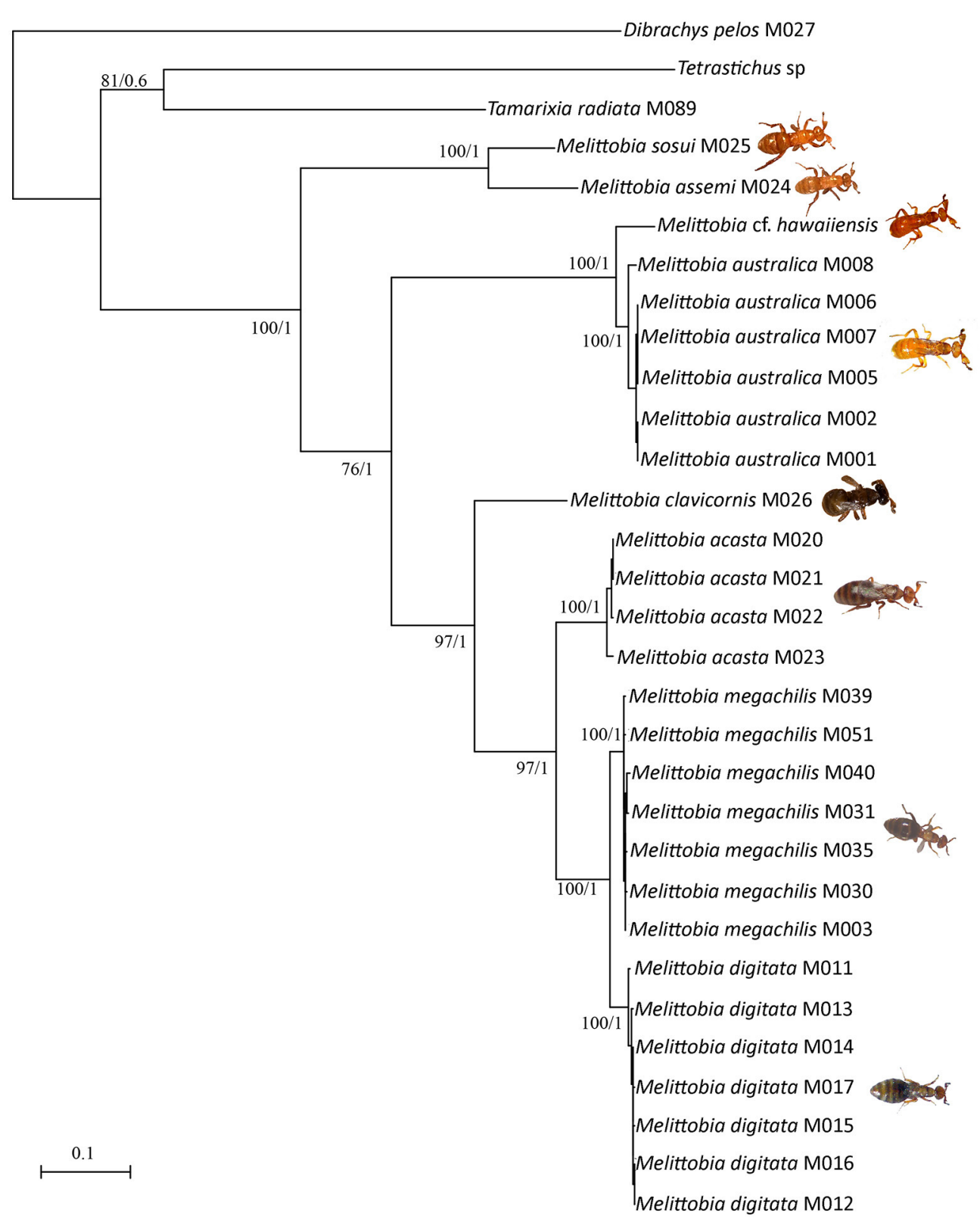

FIGURE 2 | Phylogenetic analyses. Phylogeny of Melittobia species based on phylogenetic analyses of ITS1, ITS2, and the CO1 sequences. Branch lengths are from $\mathrm{ML}$ trees. Bootstrap support values of $\mathrm{ML}$ analysis and Bayesian posterior probabilities for each branch are indicated before and after a slash, respectively.

robustly support these Melittobia species-group relationships. In contrast to Tanner et al. (2011), we were now also able to verify the $M$. hawaiiensis species-group, supporting a sister-group relationship of $M$. australica and $M$. cf. hawaiiensis due to the newly generated sequence information. On this regard, we are further investigating the latter population, which even though it is close genetically to M. australica (Figure 2) it diverges behaviorally from it (González and Parry, unpublished). Similar cases, treated as "intermediates" between $M$. australica and $M$. hawaiiensis have been previously reported by van den Assem et al. (1982) and Dahms (1984).
Our analyses further support the phylogenetic relationships among the Melittobia species-groups as shown by Tanner et al. (2011). The M. assemi species-group represents the early branching species-group within Melittobia and the $M$. hawaiiensis species-group is the sister-group to the clade comprising the M. clavicornis and the M. acasta species-group.

The results of the ancestral character reconstruction are shown in Tables 1, 2 and further in Figure 3. The reconstruction yielded no conflict between likelihood and Bayesian analyses (BA), but the likelihood approach (LA) reconstructed them with greater uncertainty (equivocal) than the Bayesian approach. 
TABLE 1 | SIMMAP ancestral state reconstruction analysis.

\begin{tabular}{lcccccc}
\hline Node & Control & $\begin{array}{c}\text { Trypoxylon } \\
\text { politum }\end{array}$ & Control & $\begin{array}{c}\text { Megachile } \\
\text { rotundata }\end{array}$ & Control & $\begin{array}{c}\text { Apis } \\
\text { mellifera }\end{array}$ \\
\hline 1 & 0.6139 & 0.3861 & 0.3920 & 0.6080 & 0.3066 & 0.6934 \\
2 & 0.9243 & 0.0757 & 0.0845 & 0.9155 & 0.0830 & 0.9170 \\
3 & 0.4150 & 0.5850 & 0.6111 & 0.3889 & 0.3719 & 0.6281 \\
4 & 0.9761 & 0.0239 & 0.9835 & 0.0165 & 0.6160 & 0.3840 \\
5 & 0.0755 & 0.9245 & 0.5943 & 0.4057 & 0.2263 & 0.7737 \\
6 & 0.0226 & 0.9774 & 0.9274 & 0.0726 & 0.3460 & 0.6540
\end{tabular}

The probability of each host-associated semiochemical being exhibited by the ancestor represented at each node in the phylogeny.

TABLE 2 | Mesquite ancestral state reconstruction analysis.

\begin{tabular}{lcccccc}
\hline Node & Control & $\begin{array}{c}\text { Trypoxylon } \\
\text { politum }\end{array}$ & Control & $\begin{array}{c}\text { Megachile } \\
\text { rotundata }\end{array}$ & Control & $\begin{array}{c}\text { Apis } \\
\text { mellifera }\end{array}$ \\
\hline 1 & 0.8688 & 0.1312 & 0.3689 & 0.6311 & 0.5000 & 0.5000 \\
2 & 0.9823 & 0.0177 & 0.1004 & 0.8996 & 0.5000 & 0.5000 \\
3 & 0.7826 & 0.2174 & 0.5869 & 0.4131 & 0.5000 & 0.5000 \\
4 & 0.9722 & 0.0278 & 0.8906 & 0.1094 & 0.5000 & 0.5000 \\
5 & 0.1044 & 0.8956 & 0.5055 & 0.4945 & 0.5000 & 0.5000 \\
6 & 0.0146 & 0.9854 & 0.8741 & 0.1259 & 0.5000 & 0.5000 \\
\hline
\end{tabular}

The probability of each host-associated semiochemical being exhibited by the ancestor represented at each node in the phylogeny.

The ancestral state reconstruction revealed both A. melliferaassociated odors and $M$. rotundata-associated odors as the potential ancestral host chemical cues exploited by the Melittobia species-group. However, while M. rotundata-associated odors are supported as the ancestral host chemical cues exploited by Melittobia for host location in both approaches (BA: 0.61, LA: 0.63 ), the support for A. mellifera-associated odors as the ancestral host chemical cues is based on the Bayesian approach (0.69) (see Table 1) while the likelihood approach is equivocal (0.5) (see Table 2).

\section{DISCUSSION}

Insect parasitoids can exploit a variety of stimuli while foraging for hosts among which chemical cues appear to play a major role (Godfray, 1994; Vinson, 1998; Fatouros et al., 2008; Colazza et al., 2014). In this study we show that macropterous females of Melittobia species clearly rely on semiochemical exploitation of host-associated cues when searching for hosts. Volatiles released by cocoons enveloping the host prepupae thus are not only relevant for M. digitata and M. acasta (Silva-Torres et al., 2005a; Cusumano et al., 2010; Glasser and Farzan, 2016), but these host semiochemicals appear to mediate the host finding behavior in several species within the genus Melittobia.

Interestingly, different Melittobia species displayed variation in terms of behavioral response toward odors emitted by leafcutter bees, mud dauber wasps, honeybees and flesh flies. The early-branching species (assemi-group: M. assemi and M. sosui) were attracted to volatiles released from the alfalfa leaf-cutter bee $M$. rotundata and $A$. mellifera, suggesting that these bee odors could be related to those emitted by the ancestral original host attacked by Melittobia wasps (see Table 2). However it is most likely that the odors associated with alfalfa leaf-cutter bee $M$. rotundata are related to those associated with the ancestral host since A. mellifera is generally attacked by Melittobia spp. only when colonies do not possess a healthy status (Matthews et al., 2009). On the contrary the most-diverged species (acastagroup: M. acasta and M. digitata) responded to semiochemicals released by cocoons enveloping $T$. politum prepupae, a common host frequently parasitized by several Melittobia species in the field (Matthews et al., 2009). These results are unlikely affected by pre-imaginal experience as previously shown that the rearing history did not influence host choice (Silva-Torres et al., 2005b). Previous studies have also shown that learning does not affect the foraging behavior of macropterous females at least in M. digitata (González et al., 2011). Organ-pipe mud dauber hosts represent large, high quality hosts compared to leaf-cutter bees (González and Matthews, 2002) and a single Trypoxylon prepupae can support the production of short-winged females yielding more than 400 offspring (most of them long winged females) per host (González et al., 2013). Thus a high host location efficiency toward mud dauber wasps seems adaptive as it can maximize the reproductive success of Melittobia wasps, taking also into account that a macropterous female usually locates, parasitizes and/or superparasitizes only a single host during her lifetime (Freeman and Ittyeipe, 1993; Matthews et al., 2009). Across the more-diverged species, (clavicornis group: M. clavicornis) wasps are attracted by both odors from alfalfa leaf-cutter bee and from organ-pipe mud dauber wasp; however the host location strategy adopted by species in the hawaiiensis group (M. australica and M. cf. hawaiiensis) is still puzzling as they apparently do not exploit volatile semiochemicals emitted by the cocoons enveloping prepupae of $T$. politum or $M$. rotundata. It is possible that species in the hawaiiensis group exploit different cues to locate their hosts, for example cues produced by a stage different than that attacked (infochemical detour sensu, Vet and Dicke, 1992). The strategy based on cues indirectly associated with the host presence appears widespread among parasitoids, which often exploit host semiochemicals from the adult stage (Noldus et al., 1991; Colazza et al., 1999; Fatouros et al., 2005). In the case of solitary bees and wasps, the adult female constructs the nest for the offspring with the aid of her mouthparts; thus it has been suggested that volatiles from the nest under construction, which are contaminated with chemicals associated with female mouthparts, can also be important in localizing suitable hosts (Cusumano et al., 2010). Unfortunately, we could not test parasitoids' attraction toward odors emitted by nest under constructions due to the technical difficulties associated in retrieving such nests. Further studies should be conducted to investigate whether the host location strategy of species in the hawaiiensis group diverged from the other Melittobia species and whether it is indeed based on indirectly associated chemical cues. Testing the nest material will be beneficial to fully understand the host location strategy adopted by Melittobia macropterous females when foraging for hosts in nature. 
A
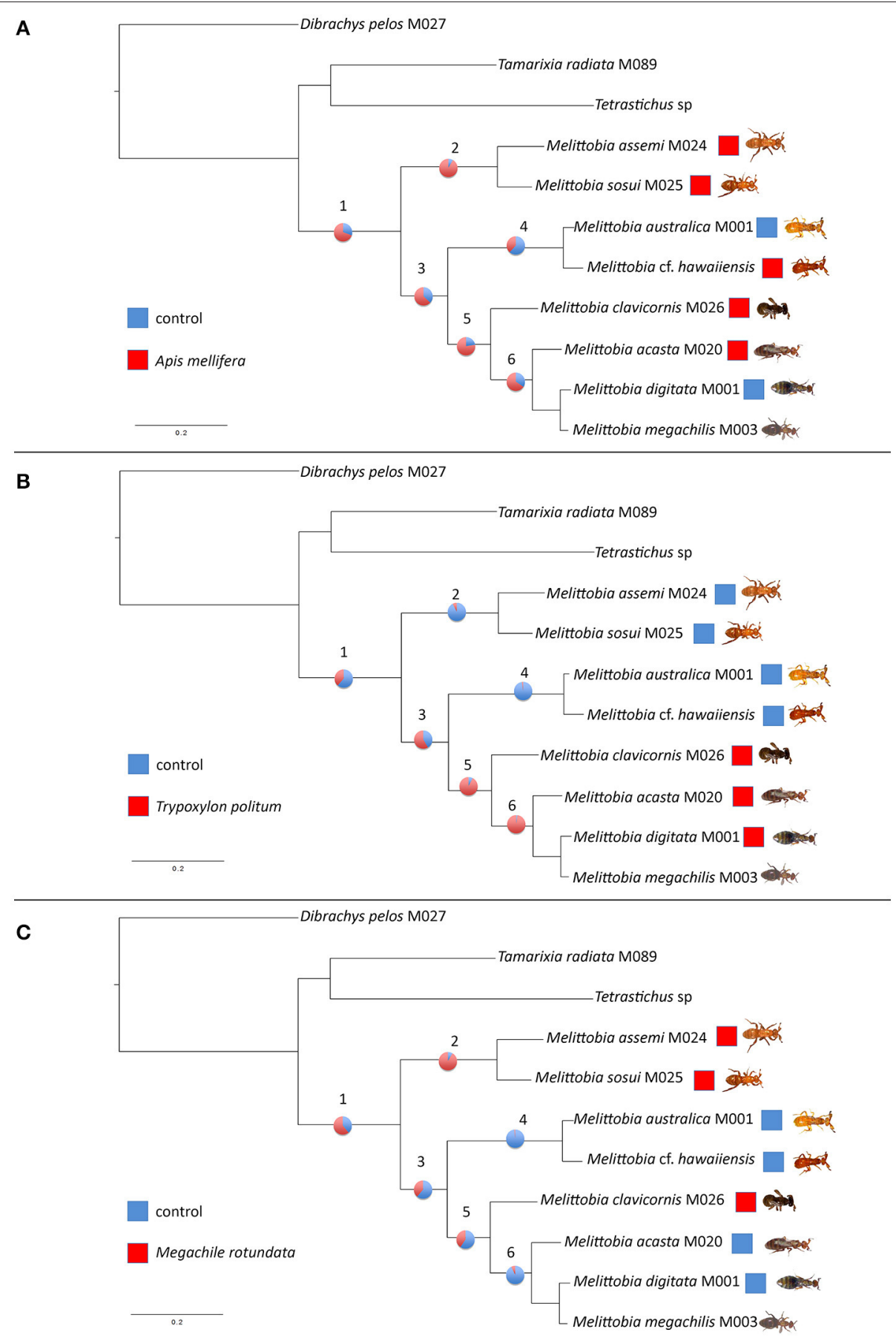

FIGURE 3 | Ancestral character reconstruction. Ancestral state reconstruction for the ancestral host-associated chemical cues exploited by the Melittobia species-group based on the Bayesian approach: (A) Apis mellifera, (B) Trypoxylon politum, and (C) Megachile rotundata. The topology is derived from the ML tree of Figure 2. Pie charts indicate the relative probabilities at respective nodes (1-6).

As expected, we found no attraction by any Melittobia species toward odors emitted by the factitious host S. bullata, indicating that macropterous females did not evolve the ability to exploit semiochemicals from the pupa of this dipteran species. However, in the laboratory, Melittobia species attack dipteran (i.e.,
Calliphoridae, Sarcophagidae, Tephritidae), lepidopterans (i.e., Tortricidae), and coleopteran (Tenebrionidae) species, but in the field some Melittobia species have been also found attacking fruit flies (Tephritidae) and even lepidopterans (i.e., Tortricidae) and roach eggs (i.e., Periplaneta americana) (González et al., 2004b, 
2013; González and Matthews, 2005b; Matthews et al., 2009). This tremendous plasticity may serve in the field to parasitize satellite flies (Sarchophagidae) and bee flies (Bombyliidae) that sometimes infest the nest of their preferred hosts, Trypoxylon mud daubers (Matthews et al., 2009). In our experiments we were surprised to found that five species of Melittobia showed a significant preference for volatiles released by prepupae of A. mellifera, regardless of the wasps' phylogenetic relationships. This finding raises the concern of Melittobia species being potential pests of pollinators as the majority of the tested species can exploit host semiochemicals to locate honeybees. However, the risks for honeybee colonies appear to be low even though Melittobia parasitoid can reproduce fine on honeybees' pupae and prepupa (Cônsoli and Vinson, 2002a,b). In fact, whereas there have been reports of Melittobia parasitizing declining hives in Europe or queen producing hives in North America (Hobbs and Krunic, 1971; Erickson and Medenwald, 1979; Jelinski and Wojtowski, 1984; de Wael et al., 1995), it has been shown that Melittobia are unable to get past the honeybee hives' effective colony defense and hygienic behavior when colony possesses a healthy status (Whitfield and Cameron, 1993). However, the risk as pests of pollinators is higher for non-Apis pollinators such as leaf-cutter bees (Megachilidae) because of the Melittobia's high reproductive potential, the ability to enter nests under construction and a strong female-biased sex ratio (typically 95\% of the offspring consist of females) (Matthews et al., 2009).

In conclusion, we have shown that host-associated volatile cues play an important role in the host location of seven Melittobia species. We have also highlighted the specificity of semiochemical exploitation across the seven Melittobia species. We are aware that the performed phylogenetic analysis to reconstruct the evolution of host location within the genus Melittobia has some limitations: for instance, not all the hosts naturally attacked or not all the parasitoid species present within the genus have been tested in this study. However, despite these limitations, this study represent an interesting new

\section{REFERENCES}

Bollback, J. P. (2006). SIMMAP: stochastic character mapping of discrete traits on phylogenies. BMC Bioinformatics 7:88. doi: 10.1186/1471-2105-7-88

Carde, R. T., and Millar, J. G. (2004). Advances in Insect Chemical Ecology. Cambridge: Cambridge University Press.

Chabi-Olaye, A., Schulthess, F., Poehling, H. M., and Borgemeister, C. (2001). Host location and host discrimination behavior of Telenomus isis, an egg parasitoid of the African cereal stem borer Sesamia calamistis. J. Chem. Ecol. 27, 663-678. doi: 10.1023/A:1010341716847

Charnov, E. L., and Stephens, D. W. (1988). On the evolution of host selection in solitary parasitoids. Am. Nat. 132, 707-722. doi: 10.1086/284883

Chernomor, O., von Haeseler, A., and Minh, B. Q. (2016). Terrace aware data structure for phylogenomic inference from supermatrices. Syst. Biol. 6, 997-1008. doi: 10.1093/sysbio/syw037

Colazza, S., Salerno, G., and Wajnberg, E. (1999). Volatile and contact chemicals released by Nezara viridula (Heteroptera: Pentatomidae) have a kairomonal effect on the egg parasitoid Trissolcus basalis (Hymenoptera: Scelionidae). Biol. Control 16, 310-317. doi: 10.1006/bcon.1999.0763

Colazza, S., Cusumano, A., Lo Giudice, D., and Peri, E. (2014). Chemoorientation responses in hymenopteran parasitoids induced by piece of information about the ecology of Melittobia species and can be the basis to extend knowledge on semiochemical use in an evolutionary perspective in the context of foraging behavior of insect parasitoids. Future investigations should combine olfactometer experiments with Gas ChromatographyMass Spectrometry analyses focusing on polar and apolar extracts of prepupae. These investigations should be conducted in the attempt to characterize the blend of semiochemicals that mediate host-attraction behavior and unravel if different Melittobia species exploit the same volatile compounds to locate common shared hosts.

\section{AUTHOR CONTRIBUTIONS}

JMG, DC, and AC conceived and designed experiments; JMG and DC performed experiments; SS and AC analyzed data; all authors interpreted results, drafted and revised the manuscript.

\section{ACKNOWLEDGMENTS}

We are indebted to Adam Novicki, John Ballis, and Ron Bittner for providing us with prepupae and pupae of honey bees and leafcutter bees. We also thank Patrick Verbaarschot for technical support with molecular analyses. Thanks to Jun Abe for his enlightening comments to an earlier manuscript. This research (and JMG and DC) was mostly supported by the California State University Agricultural Research Initiative Award (ARI 350311.9532.160; 2014-2017), CSU Fresno Provost's Assigned Time for Research (Summer 2015, 2016), and the CSU Fresno, Research, Scholarship and Creative proposal Award (2014-2016).

\section{SUPPLEMENTARY MATERIAL}

The Supplementary Material for this article can be found online at: https://www.frontiersin.org/articles/10.3389/fevo. 2017.00172/full\#supplementary-material

substrate-borne semiochemicals. Biocontrol 59, 1-17. doi: 10.1007/s10526-0139546-7

Cônsoli, F. L., and Vinson, S. B. (2002a). Clutch size, development and wing morph differentiation of Melittobia digitata Dahms (Hymenoptera: Eulophidae). Entomol. Exp. Appl. 102, 135-143. doi: 10.1046/j.1570-7458.2002.00933.x

Cônsoli, F. L., and Vinson, S. B. (2002b). Larval development and feeding behavior of the wing dimorphics of Melittobia digitata Dahms (Hymenoptera: Eulophidae). J. Hymenopt. Res. 11, 188-196.

Cook, J. M., Rokas, A., Pagel, M., and Stone, G. N. (2002). Evolutionary shifts between host oak sections and host-plant organs in Andricus gallwasps. Evolution 56, 1821-1830. doi: 10.1111/j.0014-3820.2002.tb00196.x

Cross, E. A., Stith, M. G., and Bauman, T. R. (1975). Bionomics of the organ-pipe muddauber, Trypoxylon politum (Hymenoptera: Sphecoidea). Ann. Entomol. Soc. Am. 68, 901-916. doi: 10.1093/aesa/68.5.901

Cusumano, A., Peri, E., and Colazza, S. (2016). Interspecific competition/facilitation among insect parasitoids. Curr. Opin. Insect Sci. 14, 12-16. doi: 10.1016/j.cois.2015.11.006

Cusumano, A., González, J. M., Colazza, S., and Vinson, S. B. (2010). Behavioral responses of the parasitoid Melittobia digitata to volatiles emitted by its natural and laboratory hosts. Entomol. Exp. Appl. 136, 301-307. doi: $10.1111 /$ j.1570-7458.2010.01027.x 
Dahms, E. C. (1984). A review of the biology of species in the genus Melittobia (Hymenoptera: Eulophidae) with interpretations and additions using observations on Melittobia australica. Mem. Queensl. Mus. 21, 337-360.

de Wael, L., de Greef, M., and van Laere, O. (1995). Biology and control of Melittobia acasta. Bee World 76, 72-76. doi: 10.1080/0005772X.1995.1 1099244

Dicke, M., and Grostal, P. (2001). Chemical detection of natural enemies by arthropods: an ecological perspective. Annu. Rev. Ecol. Evol. Syst. 32, 1-23. doi: 10.1146/annurev.ecolsys.32.081501.113951

Erickson, E. H., and Medenwald, R. (1979). Parasitism of queen honeybee pupae by Meliittobia acasta. J. Apic. Res. 18, 73-76. doi: 10.1080/00218839.1979.11099947

Farkas, J., and Szalay, L. (1985). Controlling of insect-parasites of alfalfa leaf cutting beestock (Megachile rotundata F., Hymenoptera, Megachilidae). Apidologie 2, $171-180$

Fatouros, N. E., Huigens, M. E., van Loon, J. J., Dicke, M., and Hilker, M. (2005). Chemical communication: butterfly anti-aphrodisiac lures parasitic wasps. Nature 433:704. doi: 10.1038/433704a

Fatouros, N. E., Dicke, M., Mumm, R., Meiners, T., and Hilker, M. (2008). Foraging behavior of egg parasitoids exploiting chemical information. Behav. Ecol. 19, 677-689. doi: 10.1093/beheco/arn011

Folmer, O., Black, M., Hoeh, W., Lutz, R., and Vrijenhoek, R. (1994). DNA primers for amplification of mitochondrial cytochrome c oxidase subunit I from diverse metazoan invertebrates. Mol. Marine Biol. Biotechnol. 3, 294-299.

Freeman, B. E., and Ittyeipe, K. (1993). The natural dynamics of the eulophid parasitoid Melittobia australica. Ecol. Entomol. 18, 129-140. doi: 10.1111/j.1365-2311.1993.tb01194.x

Glasser, S., and Farzan, S. (2016). Host-associated volatiles attract parasitoids of a native solitary bee, Osmia lignaria Say (Hymenoptera, Megachilidae). J. Hymenopt. Res. 51:249. doi: 10.3897/jhr.51.9727

Godfray, H. C. J. (1994). Parasitoids: Behavioral and Evolutionary Ecology. Princeton, NJ: Princeton University Press.

González, J. M., Matthews, R. W., and Matthews, J. R. (1985). A sex pheromone in males of Melittobia australica and M. femorata (Hymenoptera: Eulophidae). Fla. Entomol. 68, 279-286. doi: 10.2307/3494361

González, J. M., and Matthews, R. W. (2002). Development and sex ratio of Melittobia australica and $M$. digitata (Hymenoptera: Eulophidae) on Megachile rotundata (Hymenoptera: Megachilidae) and Trypoxylon politum (Hymenoptera: Sphecidae). Great Lakes Entomol. 35, 85-92.

González, J. M., Abe, J., and Matthews, R. W. (2004a). Offspring production and development in the parasitoid wasp Melittobia clavicornis (Cameron) (Hymenoptera: Eulophidae) from Japan. Entomol. Sci. 7, 15-19. doi: 10.1111/j.1479-8298.2003.00039.x

González, J. M., Terán, J. B., and Matthews, R. W. (2004b). Review of the biology of Melittobia acasta (Walker) (Hymenoptera: Eulophidae) and additions on development and sex ratio of the species. Carib. J. Sci. 40, 52-61.

González, J. M., and Matthews, R. W. (2005a). Courtship of the two female morphs of Melittobia digitata (Hymenoptera: Eulophidae). Fla Entomol. 88, 258-267. doi: 10.1653/0015-4040(2005)088[0258:COTTFM]2.0.CO;2

González, J. M., and Matthews, R. W. (2005b). An annotated bibliography of Melittobia (Hymenoptera: Eulophidae). Carib. J. Sci. 8, 1-41.

González, J. M., Cusumano, A., Williams, H. J., Colazza, S., and Vinson, S. B. (2011). Behavioral and chemical investigations of contact kairomones released by the mud dauber wasp Trypoxylon politum, a host of the parasitoid Melittobia digitata. J. Chem. Ecol. 37, 629-639. doi: 10.1007/s10886-011-9960-1

González, J. M., Aluja, M., Cusumano, A., Colazza, S., and Vinson, S. B. (2013). Evaluating the quality of the Mexican fruit-fly, Anastrepha ludens, as host for the parasitoid Melittobia digitata. Entomologia 1, 26-31. doi: 10.4081/entomologia.2013.e5

Harvey, J. A., Poelman, E. H., and Tanaka, T. (2013). Intrinsic inter-and intraspecific competition in parasitoid wasps. Annu. Rev. Entomol. 58, 333-351. doi: 10.1146/annurev-ento-120811-153622

Hildebrand, J. G. (1995). Analysis of chemical signals by nervous systems. Proc. Natl. Acad. Sci. U.S.A. 92, 67-74. doi: 10.1073/pnas.92.1.67

Hilker, M., and Meiners, T. (2006). Early herbivore alert: insect eggs induce plant defence. J. Chem. Ecol. 32, 1379-1397. doi: 10.1007/s10886-006-9057-4

Hobbs, G. A., and Krunic, M. D. (1971). Comparative behavior of 3 chalcidoid (Hymenoptera) parasites of the alfalfa leafcutter bee, Megachile rotundata, in the laboratory. Can. Entomol. 103, 674-685. doi: 10.4039/Ent103674-5
Huelsenbeck, J. P., and Ronquist, F. (2001). MRBAYES: Bayesian inference of phylogeny. Bioinformatics 17, 754-755. doi: 10.1093/bioinformatics/17.8.754

Iacovone, A., French, A. S., Tellier, F., Cusumano, A., Clément, G., Gaertner, C., et al. (2016). The role of contact chemoreception in the host location process of an egg parasitoid. J. Insect Physiol. 91, 63-75. doi: 10.1016/j.jinsphys.2016.07.001

Jelinski, M., and Wojtowski, F. (1984). Melittobia acasta Walker (Hym., Chalcidoidea, Eulophidae): a poorly known parasite on honey-bee brood. Prz. Zool. 28, 507-511.

Katoh, K., and Standley, D. M. (2013). MAFFT multiple sequence alignment software version 7: improvements in performance and usability. Mol. Biol. Evol. 30, 772-780. doi: 10.1093/molbev/mst010

Krombein, K. V. (1967). Trap-Nesting Wasps and Bees: Life Histories, Nests and Associates. Washington, DC: Smithsonian.

Kück, P., and Meusemann, K. (2010). FASconCAT: convenient handling of data matrices. Mol. Phylogenet. Evol. 56, 1115-1118. doi: 10.1016/j.ympev.2010.04.024

Maddison, W. P., and Maddison, D. R. (2017). Mesquite: a Modular System for Evolutionary Analysis. Version 3.2. Available online at: http://mesquiteproject. org/

Malyshev, S. I. (1968). Genesis of the Hymenoptera and the Phases of Their Evolution. London: Methuen \& Co. Ltd.

Matthews, R. W., Yukawa, J., and González, J. M. (1985). Sex pheromones in male Melittobia parasitic wasps: female response to conspecific and congeneric males of 3 species. J. Ethol. 3, 59-62. doi: 10.1007/BF02348166

Matthews, R. W., González, J. M., Matthews, J. R., and Deyrup, L. D. (2009). Biology of the parasitoid Melittobia (Hymenoptera: Eulophidae). Annu. Rev. Entomol. 54, 251-266. doi: 10.1146/annurev.ento.54.110807.090440

Mehrnejad, M. R., and Copland, M. J. W. (2006). Behavioral responses of the parasitoid Psyllaephagus pistaciae (Hymenoptera: Encyrtidae) to host plant volatiles and honeydew. Entomol. Sci. 9, 31-37. doi: 10.1111/j.1479-8298.2006.00151.x

Molumby, A. (1995). Dynamics of parasitism in the organ-pipe wasp, Trypoxylon politum: effects of spatial scale on parasitoid functional response. Ecol. Entomol. 20, 159-168. doi: 10.1111/j.1365-2311.1995.tb00442.x

Mumm, R., and Dicke, M. (2010). Variation in natural plant products and the attraction of bodyguards involved in indirect plant defense. Can. J. Zool. 88, 628-667. doi: 10.1139/Z10-032

Nguyen, L. T., Schmidt, H. A., von Haeseler, A., and Minh, B. Q. (2015). IQ-TREE: a fast and effective stochastic algorithm for estimating maximum likelihood phylogenies. Mol. Biol. Evol. 32, 268-274. doi: 10.1093/molbev/msu300

Noldus, L. P. J. J., Potting, R. P. J., and Barendregt, H. E. (1991). Moth sex pheromone adsorption to leaf surface: bridge in time for chemical spies. Physiol. Entomol. 3, 329-344. doi: 10.1111/j.1365-3032.1991.tb00571.x

Ronquist, F., and Huelsenbeck, J. P. (2003). MRBAYES 3: bayesian phylogenetic inference under mixed models. Bioinformatics 19, 1572-1574. doi: 10.1093/bioinformatics/btg180

Silva-Torres, C. S. A., Matthews, R. W., Ruberson, J. R., and Lewis, W. J. (2005a). Olfactory cues in host finding by Melittobia digitata (Hymenoptera: Eulophidae). Ann. Entomol. Soc. Am. 96, 595-600. doi: 10.1603/00138746(2005)098[0595:OCIHFB]2.0.CO;2

Silva-Torres, C. S. A., Matthews, R. W., Ruberson, J. R., and Lewis, W. J. (2005b). Role of chemical cues and natal rearing effect on host recognition by the parasitic wasp Melittobia digitata. Entomol. Sci. 8, 355-362. doi: 10.1111/j.1479-8298.2005.00135.x

Stireman, J. O. (2005). The evolution of generalization? Parasitoid flies and the perils of inferring host range evolution from phylogenies. J. Evol. Biol. 18, 325-336. doi: 10.1111/j.1420-9101.2004.00850.x

Tanner, D. A., González, J. M., Matthews, R. W., Bradleigh Vinson, S., and Pitts, J. P. (2011). Evolution of the courtship display of Melittobia (Hymenoptera: Eulophidae). Mol. Phylogenet. Evol. 60, 219-227. doi: 10.1016/j.ympev.2011.04.014

Thibout, E. (2005). Role of caterpillar silk thread in location of host pupae by the parasitoid Diadromus pulchellus. J. Insect. Behav. 18, 817-826. doi: 10.1007/s10905-005-8742-4

van den Assem, J., den Bosch, H. A., and Prooy, E. (1982). Melittobia courtship behavior: a comparative study of the evolution of a display. Neth. J. Zool. 32, 427-471. doi: 10.1163/002829682X00184 
Vet, L. E. M. (2001). Parasitoid searching efficiency links behaviour to population processes. Appl. Entomol. Zool. 36, 399-408. doi: 10.1303/aez. 2001.399

Vet, L. E. M., and Dicke, M. (1992). Ecology of infochemical use by natural enemies in a tritrophic context. Annu. Rev. Entomol. 37, 141-172. doi: 10.1146/annurev.en.37.010192.001041

Vinson, S. B. (1998). The general host selection behavior of parasitoid Hymenoptera and a comparison of initial strategies utilized by larvaphagous and oophagous species. Biol. Control 11, 79-96. doi: 10.1006/bcon.19 97.0601

Whitfield, J. B., and Cameron, S. A. (1993). Comparative notes on hymenopteran parasitoids in bumble bee and honey bee colonies (Hymenoptera: Apidae) reared adjacently. Entomol. News 104, 240-248.
Wyatt, T. D. (2003). Pheromones and Animal Behaviour: Communication by Smell and Taste. Cambridge: Cambridge University Press.

Conflict of Interest Statement: The authors declare that the research was conducted in the absence of any commercial or financial relationships that could be construed as a potential conflict of interest.

Copyright $\odot 2018$ González, Camino, Simon and Cusumano. This is an open-access article distributed under the terms of the Creative Commons Attribution License (CC $B Y)$. The use, distribution or reproduction in other forums is permitted, provided the original author(s) or licensor are credited and that the original publication in this journal is cited, in accordance with accepted academic practice. No use, distribution or reproduction is permitted which does not comply with these terms. 